\title{
Effects of forming agents on performance of highly-porous abrasive tools
}

\author{
Yuri Bagaiskov* \\ Volzhsky Polytechnic Institute (branch), Volgograd State Technical University, 43a, Engelsast., \\ Volzhsky, Volgograd Region, 404130, Russia
}

\begin{abstract}
Quality assurance and processing capacity are essential performance parameters of abrasive tools. It is of prime importance for grinding wheels operating at a speed of $35-60 \mathrm{~m} / \mathrm{s}$. In this case, opportunities to increase grinding efficiency without burns are associated with using high-porosity and low-hardness wheels. Artificial pore-forming agents are used to manufacture tools. The introduction of pore-forming agents decreases grinding forces and increases the maximum grinding depth without burns. The grinding ratio decreases as the content and grit size of pore-forming agents increase. Since the introduction of poreforming agents with the grit size exceeding that of the abrasive material increases the distance between the abrasive material's grains, the surface roughness of grinding with high-porosity wheels is slightly higher, which requires using wheels with a lower grit size of the abrasive material. In general, a possibility to apply deeper grinding without burns emerges, which increases capacity, ensuring the required metal-surface quality.
\end{abstract}

The operation capacity of abrasive tools, as related primarily to ensuring the processing quality and efficiency, depends on the abrasive material porosity to a great extent. It is also manifested in the increased service life of a tool both in terms of dimensional wear and breakdown $[1,2,3]$. It is especially essential for ceramic-bonded grinding wheels as they operate at rotation speeds $35 \mathrm{~m} / \mathrm{s}$ and higher and feature certain weight imbalance in the center of gravity. As a result, rupture stresses above the material's ultimate strength can occur [4]. Besides, it is commonly known that strength is related to hardness: less strong tools wear down faster in the course of grinding. On the other hand, the modern trends of increasing efficiency of such tools are associated with increasing the material's degree of structural porosity while decreasing hardness [5]. It is of particular importance for rapid processing of heavy-duty materials without burns [6]. The strength of tool composites will obviously decrease at increased porosity and decreased hardness.

Material porosity can be increased rather substantially by injection of burning [7], fusing, or dissolving artificial pore-forming agents to the molding compound while tools are being manufactured.

The degree of porosity and strength of abrasive-tool materials with various ceramic bond parameters were studied in terms of the abrasive material type and the bond type, the structure number, the abrasive grit, and content of pore-forming agents [8].

* Corresponding author: instra-ysb@rambler.ru 
In fact, the structure number determines the abrasive and bond correlation in the overall structure of the tool material: the higher the number, the less abrasive and the more bond are there at the same pore volume. The actual structure number increases in the case of introducing pore-forming agents.

It is of interest to study the degree of impact of available pore-forming agents on the performance of abrasive tools.

Grinding wheels with the following parameters have been studied: white fused alumina of grade 25A with grit size F60 $(250 \mu \mathrm{m})$, initial structure 6, hardness K-L. Correspondingly, the fusing bond of grade $\mathrm{K} 5$ was used for fused alumina; crushed fruit cores of various sizes $(400 \mu \mathrm{m}, 630 \mu \mathrm{m}$, and $800 \mu \mathrm{m})$ and amount $(7,10$, and $15 \%$ of the abrasive grain volume) were used as burning additives at the pore-forming agent temperature of $1220-1250{ }^{\circ} \mathrm{C}$.

Sizes of the tested grinding wheels: 1 (straight section) 150x20x32. Chrome-tungsten steel of grade KhVG for the production of tools has been processed. The following parameters have been determined for performance evaluation: grinding force components $P_{z}$ and $P_{y}$; performance criteria: grinding ratio $K$; surface roughness $R_{a}$; availability of burns.

The grinding ratio is calculated as the ratio of the material mass removed from the processed part to the used/ground-off mass of the wheel (with consideration of trueing). The higher the grinding ratio is, the higher is the grinding wheel capacity.

The values of the grinding force components $P_{z}$ and $P_{y}$ are specified in the Table 1 . The highest values of the grinding force components have been obtained for the basic wheel. Besides, the maximum depth of burn-free grinding of the processed part with this wheel has amounted to $0.02 \mathrm{~mm}$ per double stroke. Dashed burns occur and aggravate at $0.03 \mathrm{~mm}$ per double stroke and higher. The introduction of pore-forming agents increases the maximum burn-free grinding depth up to $0.04 \mathrm{~mm}$ per double stroke. It is apparent that the grinding forces decrease by $6-10 \%$ in the case of grinding with high-porosity wheels; the more pore-forming agents are used, the higher the decreasing extent is. The grinding forces also decrease as the grit size increases.

Table 1. Grinding forces $\left(P_{z}, P_{y}\right)$ of steel $\mathrm{KhVG}$ for grinding wheels with varions porosity

\begin{tabular}{|c|c|c|c|c|c|c|c|c|}
\hline \multirow{3}{*}{$\begin{array}{l}\text { Structure } \\
\text { number }\end{array}$} & \multicolumn{2}{|c|}{ Pore-forming agents } & \multicolumn{3}{|c|}{$P_{z}, \mathrm{~N}$} & \multicolumn{3}{|c|}{$P_{y}, \mathrm{~N}$} \\
\hline & \multirow[b]{2}{*}{$\begin{array}{l}\text { Grit size, } \\
\mu \mathrm{m}\end{array}$} & \multirow{2}{*}{$\begin{array}{l}\text { Amount, } \% \text { of } \\
\text { the abrasive- } \\
\text { grain mass }\end{array}$} & \multicolumn{6}{|c|}{ Grinding depth, mm per double stroke } \\
\hline & & & 0.02 & 0.03 & 0.04 & 0.02 & 0.03 & 0.04 \\
\hline 6 & - & - & 47 & 65 & - & 105 & 146 & - \\
\hline \multirow[t]{6}{*}{10} & 250 & 10 & 46 & 62 & 76 & 104 & 149 & 173 \\
\hline & 400 & 10 & 44 & 58 & 73 & 103 & 136 & 170 \\
\hline & 630 & 10 & 44 & 57 & 71 & 102 & 135 & 168 \\
\hline & 800 & 10 & 43 & 57 & 70 & 102 & 135 & 166 \\
\hline & 800 & 7 & 45 & 60 & 74 & 103 & 140 & 172 \\
\hline & 800 & 15 & 43 & 56 & 68 & 102 & 130 & 162 \\
\hline
\end{tabular}

Figures 1 and 2 show the dependence of the grinding ratio on the grinding depth at various extent and grit sizes of pore-forming agents as compared to the wheel of initial structure 6. 


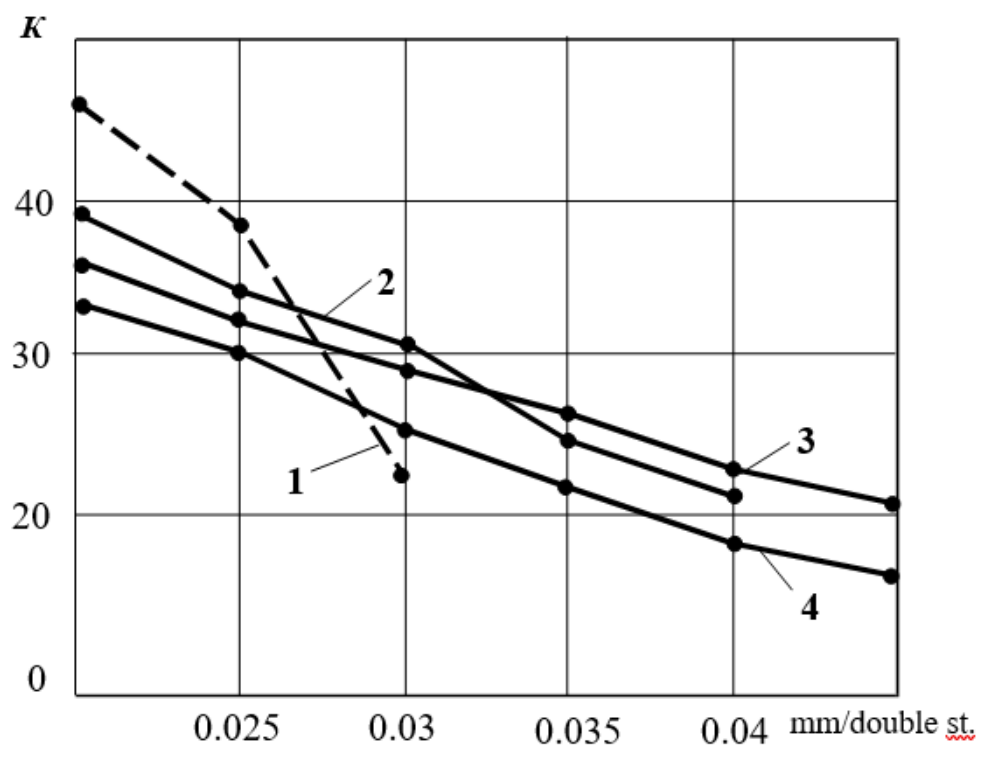

Fig. 1. Grinding ratio vs. grinding depth at various extent of pore-forming agents: $7 \%(2), 10 \%(3)$, and $15 \%$ (4) as compared to the wheel of structure $6(1)$

The grinding ratio values of the grinding wheels made of steel KhVG correlate clearly with the values of the grinding force components: higher values of $K$ correspond to higher values of the forces. In the case of grinding with the basic wheel, $K$ is higher in this area than that of grinding with high-porosity wheels. The values of $K$ decrease for all wheels as the grinding depth increases.

The most intensive drop of $K$ occurs on the basic wheel: it is lower than that of highporosity wheels at the depth of $0.03 \mathrm{~mm}$ per double stroke.

The following influence pattern of the content and grit size of pore-forming agents on the grinding ratio has been demonstrated: the grinding ratio decreases as the content and grit size of pore-forming agents increase.

The obtained correlation between grinding ratio $K$ for the basic grinding wheel (1) without pore-forming agents and for the wheel (2) with pore-forming agents to the extent of $15 \%$ of the abrasive material mass and grinding depth $t$ is as follows:

$$
\begin{gathered}
K_{1}=-2400 t+95,833 \\
K_{2}=5357 t^{2}-1148.2 t+52.268
\end{gathered}
$$

The formula for the grinding wheel (3) with pore-forming agents of the grit size 800 $\mu \mathrm{m}$ :

$$
K_{3}=1 E+06 t^{3}-124921 t^{2}+3296.3 t+3.746
$$




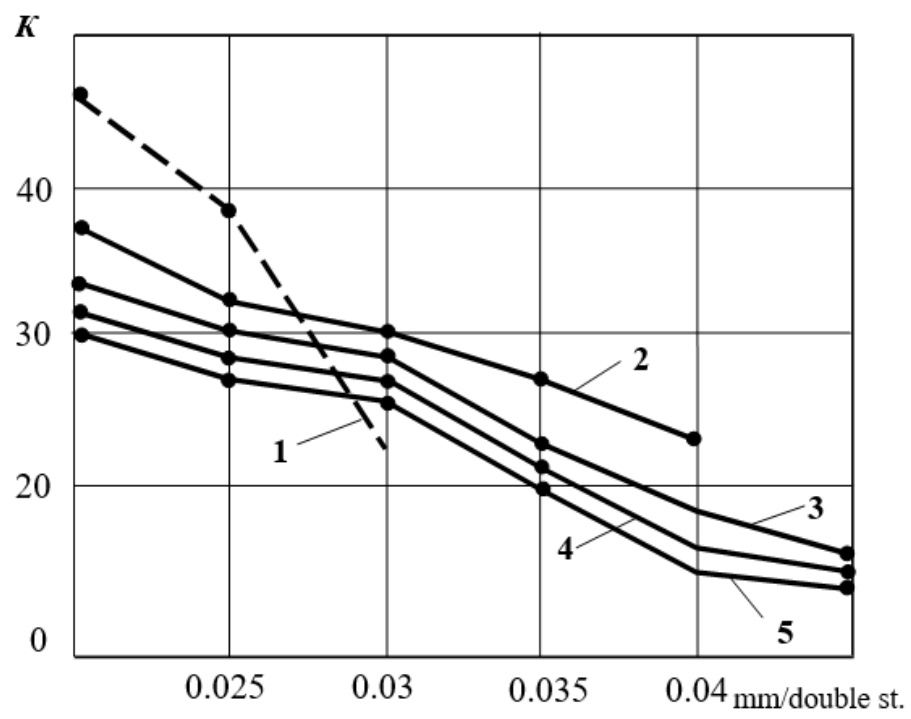

Fig. 2. Grinding ratio vs. grinding depth at various grit-sizes of pore-forming agents: 250 (2), 400 (3), 630 (4), and $800 \mu \mathrm{m}(5)$ as compared to the wheel of structure $6(1)$

Since the introduction of pore-forming agents with the grit size exceeding that of the abrasive material $(800$ and $250 \mu \mathrm{m})$ increases the distance between the abrasive material's grains, the surface roughness of grinding with high-porosity wheels is slightly higher than that of the basic wheels (Fig. 3 and 4). The surface roughness value increases slightly as the content and grit size of pore-forming agents increase. The roughness is affected by the grit size of pore-forming agents most notably. As the grit size increases from 250 to $800 \mu \mathrm{m}$, the value of surface roughness $R_{a}$ increases by a factor of $1.25-1.3$; in case the amount of pore-forming agents changes from 7 to $15 \%, R_{a}$ varies by $10 \%$ at most. Besides, the roughness increases at higher values of the cutting depth, which is typical for using highporosity grinding wheels.

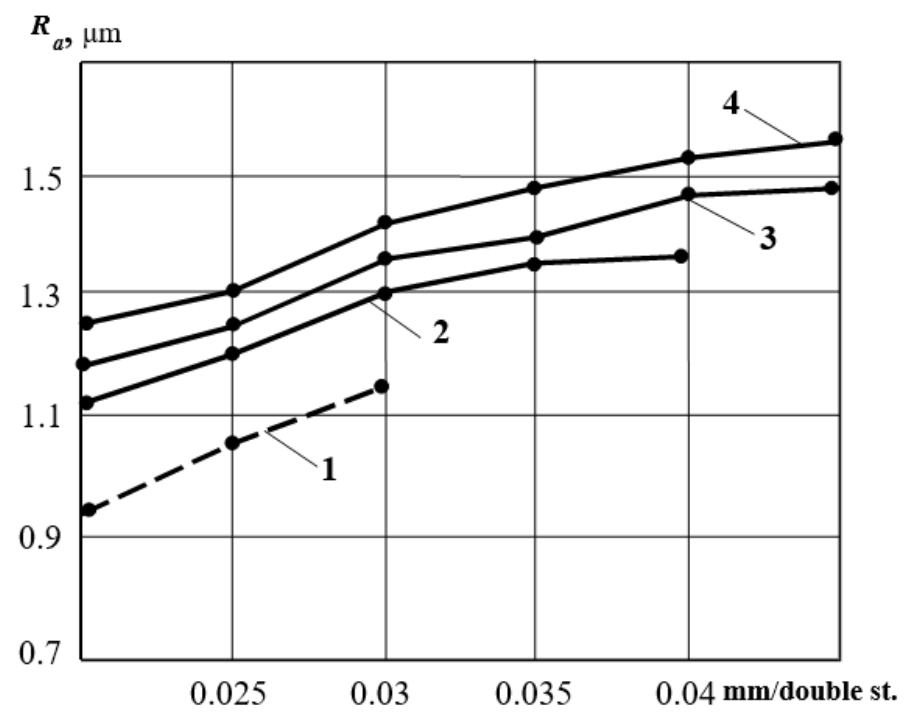

Fig. 3. Processed surface roughness $R_{a}$ vs. grinding depth at various extent of pore-forming agents: 7 $\%(2), 10 \%(3)$, and $15 \%$ (4) as compared to the wheel of structure $6(1)$ 
The functions of surface roughness $R_{a}$ after processing by the basic grinding wheel (1) and by the wheel containing $15 \%$ of pore-forming agents (2) and the grinding depth are as follows:

$$
\begin{gathered}
R_{\mathrm{a} 1}=21 t+0.5183 \\
R_{\mathrm{a} 2}=-2148 t^{3}+1944.4 t^{2}-41.838 t+1.4792
\end{gathered}
$$
(3):

The formula for the grinding wheel with pore-forming agents of the grit size $800 \mu \mathrm{m}$

$$
R_{\mathrm{a} 3}=-28889 t^{3}+2938 t^{2}-77.73 t+1.7724
$$

In general, it is necessary, all other things being equal, to decrease the abrasive-material grit size of high-porosity tools by 1 or 2 numbers due to the negative effect of increased grinding-wheel porosity on the roughness of the processed surface.

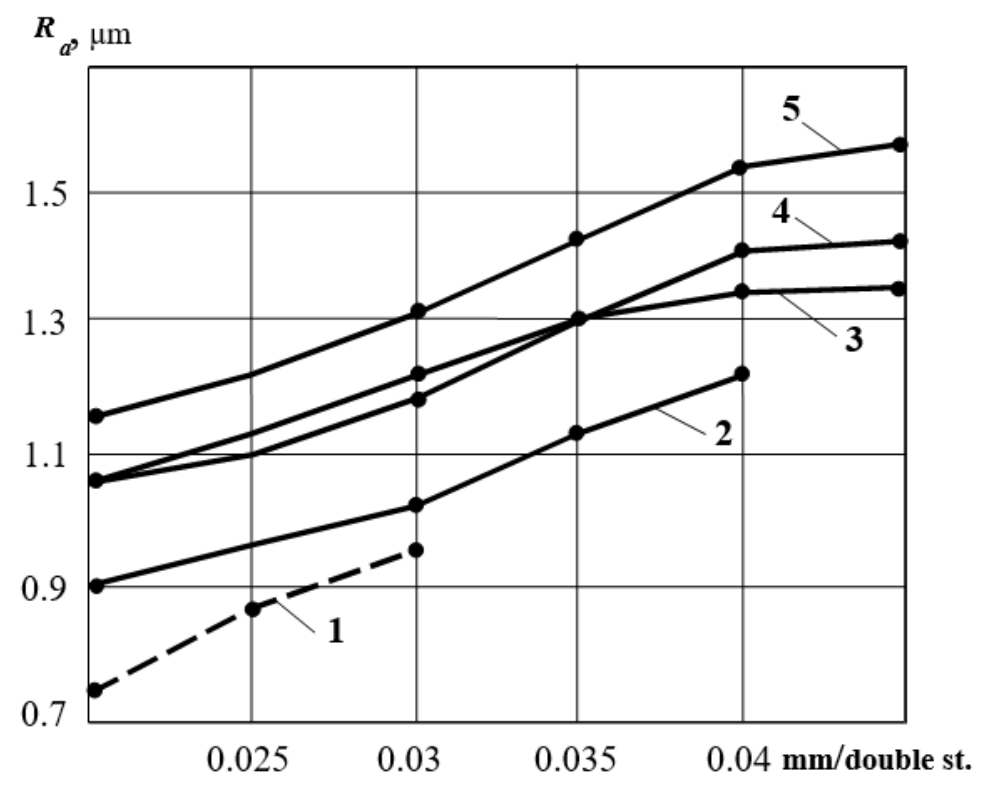

Fig. 4. Processed surface roughness $R_{a}$ vs. grinding depth at various grit-sizes of pore-forming agents: 250 (2), 400 (3), 630 (4) and $800 \mu \mathrm{m}(5)$ as compared to the wheel of structure 6 (1)

The correlations between the grinding ratio and surface roughness and grit size $d_{n}$ and extent $V_{n}$ of pore-forming agents have been developed. Such correlations for grinding depth $\mathrm{t}=0.04 \mathrm{~mm}$ per double stroke are as follows:

$$
\begin{gathered}
K=-0.0001 d_{n}^{3}+0.0248 d_{n}^{2}-1.4989 d_{n}+47.13 \\
K=-0.6327 V_{n}+27.582 \\
R_{a}=5 E-0.6 d_{n}^{3}-0.0008 d_{n}^{2}+0.0477 d_{n}+0.4966 \\
R_{a}=-0.0035 V_{n}^{2}+0.0995 V_{n}+0.825
\end{gathered}
$$

Thus, the obtained correlations make it clear that the performance of high-porosity abrasive tools depends heavily on the porosity degree of the composition material, i.e. the content and grit size of pore-forming agents. As those parameters increase, the cutting force and grinding ratio, in other words, performance, decrease. On the other hand, a possibility 
to apply deeper grinding without burns emerges, which increases capacity, ensuring the required metal-surface quality.

It is advisable, all other things being equal, to decrease the abrasive-material grit size of tools by 1 or 2 numbers due to the negative effect of increased grinding-wheel porosity on the processed surface roughness.

The revealed correlations generally apply to high-porosity tools made of other abrasive materials, with other grit sizes, other pore-forming agents, as well to processing of other metals.

\section{References}

1. A. Garshin, S. Fedotova, Abrasive Materials and Tools. Manufacturing

Procedure:Instructional Aid (Polytechnic University Press, SPb, 2008)

2. V. Schegolev, M. Ulanova, Elastic Abrasive Tools (Mashinostroenie, Leningrad

Division, L., 1984)

3. Yu. Kovalchuku, Design Basis and Manufacturing Process of Abrasive and Diamond

Tools (Mashinostroyenie, M., 1984)

4. L. Brautman, R. Krok, Composite Materials. Destruction and Fatigue ( M.: Mir, 1978)

5. Yu. Bagaiskov, Analysis of Porous Structure Forming Features of Abrasive Tools, Collected Papers of the Conference Abrasive Machining Processes, Abrasive Tools and Materials, Volzhsky, pp. $67-69$ (1999)

6. V. Ostrovsky, Theoretical Basis of Grinding (Leningrad State University Press, L., 1981)

7. A.S. 1812087, MKI B24D 3/14. Mixture for Manufacture of Porous Abrasive Tools, V. Manunin, Yu. Bagaiskov, A. Lezhnev, T. Dulichenko. Publ. on 4/30/93, Newsletter No. 16 8. Yu. Bagaiskov, V. Shumyacher Performance Increase of Devices Made of Abrasive Composite Materials (Volzhsky Institute of Civil Engineering and Technologies (branch) of Volgograd State University of Architecture and Civil Engineering, Volgograd, 2005) 